\title{
PENGUNGKAPAN PEMANFAATAN DANA CORPORATE SOCIAL RESPONSIBILITY UNTUK PENCAPAIAN MAQASHID SYARIAH PADA PT. PLN PERSERO
}

\author{
THE USE OF CORPORATE SOCIAL RESPONSIBILITY FUND FOR THE \\ ACHIEVEMENT OF SHARIA MAQASHID AT PT. PLN PERSERO
}

\author{
Siti Humairoh, Efri Syamsul Bahri, Ahmad Bisyri Syakur \\ Sekolah Tinggi Ekonomi Islam SEBI, Indonesia \\ Jl. Raya Bojongsari, Depok Jawa Barat 16517 Indonesia \\ humhum1453@gmail.com, efri.sb@sebi.ac.id, bisyri2002@yahoo.com
}

\section{Rianti Pratiwi}

School of Accounting Royal Melbourne Institute of Technology RMIT University

124 La Trobe St, Melbourne VIC 3000 Australia

rianti.pratiwi@rmit.edu.au

Naskah diterima 04 Agustus 2020, di-review 18 September 2020, disetujui 31 Desember 2020

\begin{abstract}
Research on disclosure of Corporate Social Responsibility (CSR) in relation to Maqashid Sharia in State-Owned Enterprises (BUMN) is still rarely conducted, even though the contribution of BUMN has been felt by the community for its benefits and Maslahah. This research aims to describe disclosure of the use of corporate CSR funds in achieving Maqashid Syariah. The research method uses qualitative and descriptive approaches. The technique of data collection are interviews, observation, and literature study. The data validity was done by triangulation. This research uses CSR program data in 2018. The results show that PT. PLN Persero uses CSR Funds contibuted to the achievement of Maqashid Syariah. CSR funds are allocated for five aspects of Maqashid Syariah, namely: protecting religion (hifdz inen), protecting life (hifdz nafs), protecting intelligence (hifdz aql), protecting children (hifdz nasl), and protecting property (hifdz maal). Based on this disclosure, the use of CSR funds for the achievement of the largest Sharia Maqashid is allocated for the aspect of protection of offspring (hifdz nasl). The allocation of CSR funds is IDR 34,168,729,546, or 26.93\%. Meanwhile, the smallest amount of funds in the aspect of religious protection (hifdz in) is Rp. 18,046,879,497 or 14.22\%. From this research, new insights are obtained about the contribution of CSR Funds to the achievement of Maqashi Syariah. Therefore, further research is needed to measure the effect of CSR funds on the achievement of Maqashid Syariah using other methods. In addition, further research can add data over several years and add the number of objects to several other state-owned companies.
\end{abstract}

Keywords: Disclosure, Corporate Social Responsibility, Maqasid Sharia

Abstrak: Penelitian tentang pengungkapan tanggungjawab sosial perusahaan (CSR) dalam kaitan dengan Maqashid Syariah pada Badan Usaha Milik Negara (BUMN) masih jarang dilakukan, padahal kontribusi BUMN sudah dirasakan manfaat dan maslahahnya oleh masyarakat. Penelitian tentang pengungkapan CSR dalam kaitan dengan Maqashid Syariah pada perusahaaan BUMN masih jarang dilakukan, padahal kontribusi BUMN sudah dirasakan manfaat dan maslahahnya oleh masyarakat. Penelitian ini bertujuan untuk menggambarkan pengungkapan penggunaan dana CSR perusahaan dalam mencapai Maqashid Syariah. Metode penelitian menggunakan kualitatif dan pendekatan deskriptif. Teknik pengumpulan data melalui wawancara, observasi, dan studi pustaka. Keabsahan data dilakukan secara triangulasi. Penelitian in menggunakan data program CSR pada tahun 2018. Hasil penelitian menunjukkan PT. PLN Persero menggunakan Dana CSR untuk berkontribusi pada 
pencapaian Maqashid Syariah. Dana CSR dialokasikan untuk lima aspek Maqashid Syariah, yaitu: melindungi agama (hifdz diin), melindungi kehidupan (hifdz nafs), melindungi kecerdasan (hifdz aql), melindungi anak (hifdz nasl), dan melindungi properti (hifdz maal). Berdasarkan pengungkapannya, penggunaan Dana CSR untuk pencapaian Maqashid Syariah terbesar dialokasikan untuk aspek perlindungan keturunan (hifdz nasl). Alokasi nilai bantuan sebesar Rp34.168.729.546, atau 26,93\%. Sedangkan jumlah bantuan yang paling sedikit adalah dalam aspek perlindungan agama (hifdz diin) dengan nilai bantuan Rp18.046.879.497 atau 14,22\%. Dari penelitian ini diperoleh wawasan baru datatentang kontribusi Dana CSR untuk pencapaian Maqashi Syariah. Oleh karena itu, diperlukan Penelitian lebih lanjut untuk mengukur pengaruh dana CSR pada pencapaian Maqashid Syariah menggunakan metode lain. Selain itu, penelitian selanjutnya dapat menambahkan data dalam beberapa tahun dan menambahkan jumlah obyek pada beberapa perusahaan milik negara lainnya.

Kata Kunci: Pengungkapan, Tanggung Jawab Sosial Perusahaan, Maqasid Syariah

\section{PENDAHULUAN}

\section{Tstilah Corporate Social Responsibility (CSR) 1 menurut Edi Suharto (2008); (A. C. Hadi,} 2016); (Marnelly, 2012) digunakan pertama kali tahun 1970-an. Istilah CSR menjadi terkenal pada tahun 1998 dengan hadirnya buku yang ditulis oleh John Elkingtong dengan judul Cannibals with Forks: The Triple Bottom Line in 21st Century Business. Di dalam buku tersebut, dijelaskan menegnai tiga komponen penting dalam pembangunan berkelanjutan, yaitu: economic growth, environmental protection, dan social equity. Gagasan awal yang berasal dari The World Commission on Environment and Development (WCED) kemudian dipopulerkan dengan istilah 3P, yang terdiri dari profit, planet, dan people.
Menurut Widjaja \& Pratama (2008); (Nayenggita et al., 2019), munculnya CSR disebabkan karena faktor ketidakpercayaan masyarakat terhadap perusahaan dari aspek kegiatan usaha. Oleh karena itu, gagasan utama dari dari 3P dalam konteks sustainable development adalah perusahaan yang baik bukan hanya mengejar keuntungan semata, tetapi juga mesti peduli terhadap pelestarian lingkungan (people) dan kesejahteraan masyarakat (people). Selanjutnya, menurut (Mihriban \& Harun, 2017), sistem Triple Bottom Line (TBL), berkembang menjadi tiga dimensi antara lain: ekonomi, sosial, dan lingkungan, sebagaimana diilustrasikan pada

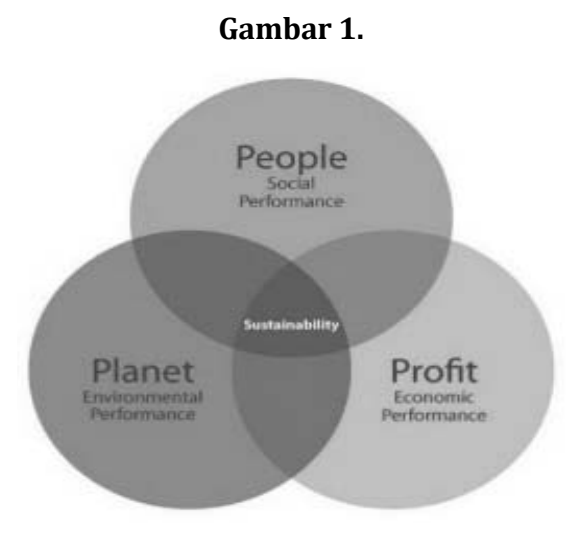

Formula Triple Bottom Line 3P Sumber: (Mihriban \& Harun, 2017)

118| Siti Humairoh, Efri Syamsul Bahri, Ahmad Bisyri Syakur, Rianti Pratiwi 
Seiring dengan semakin berkembangnya CSR, mendapat perhatian dari para peneliti. CSR dalam jangwa panjang mempunyai pengaruh positif terhadap keterlibatan karyawan, lingkungan, pemerintah, dan masyarakat (Türker, 2015), memberikan dampak positif pada kinerja keuangan perbankan (Maqbool \& Zameer, 2018), dan berpengaruh positif terhadap respons investor (Kusumo \& Juniarti, 2015). Oleh karena itu, ada keterkaitan yang erat antara CSR dengan praktik Pembangunan Berkelanjutan (Pedoman CSR, 2010), (Mitra \& Schmidpeter, 2020),

Studi (A. C. Hadi, 2016) menunjukkan kesadaran terhadap tanggung jawab sosial perusahaan terus mengalami peningkatan dalam bentuk program dan berbagai aktivitas yang digelar baik oleh perusahaan swasta mapun pemerintah. Hal ini sebagai bentuk akuntabilitas dan keterbukaan dalam pelaksanaan CSR serta upaya untuk membangun legitimasi terhadap stakeholder (N. Hadi, 2011).

Di Indonesia, perkembangan implementasi CSR diikuti dengan perkembangan regulasi. Bahkan, Indonsia menjadi negara pertama di dunia yang menerapkan pendekatan wajib terhadap CSR (Kriyantono, 2015), yang terdapat dalam beberapa peraturan. Pertama, peraturan CSR terdapat pada Undang-Undang Nomor 40 tahun 2007 tentang Perseroan Terbatas pasal 74 ayat 1 . Kedua, CSR juga di atur di dalam UndangUndang Nomor 25 tahun 2007 tentang Penanaman Modal dalam pasal 15. Ketiga, peraturan CSR juga terdapat pada Keputusan Menteri Negara Badan Usaha Milik Negara (BUMN) Nomor KEP04/MBU/2007 tentang Program Kemitraan Badan Usaha Milik Negara dengan Usaha Kecil dan Program Bina Lingkungan (PKBL). Dengan demikian, praktik CSR mempunyai legitimasi yang kuat untuk dijalankan.

Konsep TBL sebagaimana dijelaskan di atas, sejalan dengan konsep Maqashid Syariah yang dijelaskan oleh Ibn Qayyim Al-Jauziyah (1973); (Syafii et al., 2012) bahwa dasar syariah adalah untuk mewujudkan manfaat bagi masyarakat. Artinya, dalam perspektif Islam, keberhasilan pengusaha dan perusahaan tidak hanya diukur dari segi kesuksesan materi, namun juga diukur dari pencapaian terhadap tanggungjawab sosial.

Salah satu hasil penelitian tentang hubungan antara CSR dengan pencapaian Maqashid Syariah adalah yang dilakukan oleh (Yaacob \& Azmi, 2012) dengan responden adalah pengusaha Muslim di Malaysia mendapati ada hubungan yang signifikan antara pencapaian pengusaha dengan tanggungjawab sosial yang dijalankannya.

Menurut (Čavalić, 2018) dasar moral CSR dalam Islam disebut dengan Ihsan, yang dalam istilah Arab bermakna kesempurnaan atau keunggulan. Selanjutnay, aktivitas perusahaan dalam persepktif Islam harus tertanam tujuan sosial, dan kelestarian lingkungan sebagai bentuk implementasi dari Maqashid Syariah (Nugroho et al., 2018). Oleh karena itu, menurut (K. Hadi, 2012), dalam pandangan Islam perlu ada keselaran antara tujuan perusahaan dengan tujuan hidup seorang muslim. Dalam istilah lain disebut dengan falah yang menghendaki diraihnya keberhasilan di dunia dan di akhirat.

Bentuk implementasi dari falah tersebut adalah mashlahah yang dijalankan melalui aktivitas yang sesuai dengan Maqashid Syariah. 
Dalam konteks CSR, pelaporan CSR dapat diukur melalui Maqashid Syariah Indeks (MSI). Keterkaitan konsep ini didukung dengan adanya konsep TBLyang mencakup dimenasi ekonomi, sosial, dan lingkungan.

Penelitian (Finarti \& Putra, 2015) dengan menggunakan sampel pada CSR pada BRI Syariah menunjukkan adanya relevansi CSR dengan dengan Maqashid Syariah yang mencakup lima dimensi Maqashid Syariah, yaitu: menjaga agama (hifdz diin), menjaga jiwa (hifdz nafs), menjaga akal (hifdz aql), menjaga keturunan (hifdz nasl), dan menjaga harta (hifdz maal).

Penelitian tentang Pengungkapan CSR dalam kaitan dengan Maqashid Syariah pada perusahaaan BUMN masih jarang dilakukan, padahal kontribusi BUMN sudah dirasakan manfaat dan mashlahahnya oleh masyarakat. Untuk itu, penelitian ini menggunakan obyek pada PT. PLN Persero yang merupakan salah satu perusahaan BUMN. PT. PLN Persero menjadi pilihan obyek dalam penelitian ini karena mempunyai program CSR yang terdiri dari dimensi 3P yaitu: ekonomi, sosial, dan lingkungan.

\section{Kerangka Konseptual}

\section{Corporate Social Responsibility}

Menurut Komisi Eropa (2011), (Masoud, 2017) CSR mengintegrasikan antara masalah sosial, lingkungan, dan operasi bisnis serta interaksi dengan pemangku kepentingan yang dilakukan secara sukarela. CSR mencakup ekspektasi ekonomi, hukum, etika, dan filantropis (Carroll, 1979), menjadi cara bisnis secara konsisten menciptakan nilai bersama dalam masyarakat melalui pengembangan ekonomi, tata kelola yang baik, responsifitas pemangku kepentingan, dan peningkatan lingkungan (Visser, 2011).

Lebih lanjut menurut (Saifi, 2020), CSR merupakan bentuk tanggungjawab moral perusahaan kepada pemangku kepentingan perusahaan. Oleh karena itu, menurut (R. A. Putri \& Christiawan, 2014) inti dari CSR adalah etika bisnis, dimana perusahaan mempunyai kewajiban secara berkelanjutan kepada pemangku kepentingan. Dengan menjalankan kewajiban tersebut, maka diharapkan perusahaan mampu untuk terus tumbuh, hidup, beroperasi, bertahan, dan memperoleh keuntungan.

Dengan adanya penekanan CR pada aspek integrasi ketiga sektor dan interaksi dengan pemangku kepentingan, tujuan CSR juga mempunyai dimensi yang lebih luas. Beberapa pandangan tentang tujuan CSR disebutkan sebagai berikut: untuk menciptakan standar kehidupan yang lebih tinggi (Kamil \& Herusetya, 2012), mendapatkan kesejahteraan sosial (Kriyantono, 2015), dan menjadi strategi dalam menciptakan legitimasi, reputasi, dan keunggulan kompetitif (Maqbool \& Zameer, 2018).

\section{Pengungkapan}

Pengungkapan tanggungjawab sosial didefinisikan sebagai laporan aktivitas tanggung jawab social (Hadi, 2011:206), (Dermawan \& Deitiana, 2014). Tujuan pengungkapan ada dua, yaitu meningkatkan reputasi serta nilai dari perusahaan (R. A. Putri \& Christiawan, 2014). Pengungkapan yang dilakukan perusahaan, menurut (Purwanto, 2011) dibadi menjadi dua jenis. Pertama, disebut dengan pengungkapan 
wajib (mandatory disclosure) dan pengungkapan sukarela (voluntary disclosure). Pengungkapan wajib mengilustrasikan CSR sesuai dengan peraturan dan standar yang ada. Menurut Sulaiman dan Willet (2003), Suhendi dan Indriastuti (2014), (Zanariyatim et al., 2019), pengungkapan CSR merupakan informasi wajib yang harus diungkapkan.

Berdasarkan Stakeholder Theory, menurut (Roberts, 1992); (Wuttichindanon, 2017), pengungkapan CSR ditentukan oleh tiga dimensi, antara lain: pemangku kepentingan, postur strategis, dan kinerja ekonomi baik pada masa lalu maupun yang sekarang.

Sedangkan, berdasaran Teori Sinyal (Sindhudiptha and Yasa, 2013), (Saifi, 2020), CSR menjadi alasan perusahaan untuk memberikan informasi kepada pihak luar. Dalam hal ini, pengungkapan program CSR (Saifi, 2020) merupakan sinyal bagi perusahaan untuk menarik pihak eksternal. Sinyal yang dipancarkan ini diharapkan memberikan pengaruh positif kepada pihak eksternal yang akhirnya mampu mempengaruhi kinerja perusahaan.

Di dalam Undang-Undang Nomor 40 Tahun 2007 Pasal 66 ayat (2) secara eksplisitmenyebutkan pengertian tentang pengungkapan wajib dan pengungkapan sukarela. Pengungkapan wajib diartikan sebagai pengungkapan informasi yang berkaitan dengan aktivitas/keadaan perusahaan yang bersifat wajib dan dinyatakan dalam peraturan hukum. Sedangkan pengungkapan sukarela diartikan sebagai pengungkapan berbagai informasi yang berkaitan dengan aktivitas/keadaan perusahaan secara sukarela.
Selain regulasi, Indonesia juga telah mempunyai pedoman pedoman pengungkapan pertanggungjawaban sosial. Pedoman ini dikeluarkan oleh Ikatan Akuntan Indonesia (IAI) dalam bentuk Pernyataan Standar Akuntansi Keuangan (PSAK) No.1 (Revisi 2009). Di dalam PSAK No.1 (Revisi 2009) paragraph 12 (Purwanto, 2011) disebutkan bahwa "Entitas dapat pula menyajikan, terpisah dari laporan keuangan, laporan mengenai lingkungan hidup dan laporan nilai tambah (value added statement), khususnya bagi industri dimana faktor-faktor lingkungan hidup memegang peranan penting dan bagi industri yang menganggap karyawan sebagai kelompok pengguna laporan yang memegang peranan penting".

\section{Stakeholder Theory}

Pirsch et al (2007), (Kusumo \& Juniarti, 2015) berpendapat bahwa berdasarkan Stakeholder Theory keberlanjutan dan kesuksesan suatu perusahaan akan mampu diraih dengan cara memenuhi kebutuhan pemangku kepentingan. Lebih lanjut Freeman (1984), (Kusumo \& Juniarti, 2015) menjelaskan bahwa yang dimaksud dengan pemangku kepentingan dalam hal ini adalah individu dan kelompok dan individu baik yang mempunyai pengaruh maupun yang dipengaruhi agar tujuan organisasi bisa diwujudkan.

Berdasarkan Stakeholder Theory, maka setiap orang yang berada dalam afiliasi perusahaan baik yang memperoleh manfaat maupun yang menderita kerusakan dari operasi perusahaan, ataupun para pihak yang hak-haknya dipertimbangkan atau diabaikan didefinisikan sebagai pemangku kepentingan (Mihriban \& Harun, 2017). 
Untuk itu, menurut Lako (2011), (Saifi, 2020), kemampuan untuk menyeimbangkan berbagai kepentingan pemangku kepentingan sangat menentukan keberhasilan suatu perusahaan. Perusahaan mesti mampu menjaga pertumbuhan pangsa pasar, penjualan, dan keuntungan agar mampu memberikan keseimbangan kepada lingkungan dan masyarakat sekitarnya sebagai bentuk tanggung jawab kepada stakeholders.

\section{Legitimacy Theory}

Gary et al, (1996), (Saifi, 2020) menjelaskan bahwa legitimasi adalah sistem manajemen perusahaan yang diarahkan untuk menyelaraskan dengan komunitas, pemerintah, individu, dan kelompok masyarakat. Legitimasi juga diartikan sebagai keadaan psikologis keberpihakan terhadap lingkungan sekitarnya. Operasi perusahaan, menurut (Suchman, 1995: 571); (Mihriban \& Harun, 2017) dilegitimasi ketika mereka terkait, dan diterima oleh masyarakat.

Berdasarkan Legitimacy Theory, pengungkapan CSR menjadi perlukan agar perusahaan nilai positif dan legitimasi dari masyarakat. (A. K. Putri et al., 2016) Terkait dengan hal tersebut, maka Barkemeyer (2007); (A. K. Putri et al., 2016) menekankan bahwa kekuatan Legitimacy Theory terletak kapabilitas perusahaan dan faktor budaya yang membentuk tekanan institusi sesuai dengan konteksnya.

\section{Maqashid Syariah}

Maqashid Syariah merupakan penggabungan dari kata maqashid, dan kata syariah. Maqashid artinya maksud dan tujuan, sedangkan syariah diartikan sebagai sumber kehidupan jiwa dan kebahagiaan (Al-Khadimi, 2001), (Rizki Febriadi, 2017), (Bahri et al., 2019). Selanjutnay, menurut Imam al-Syatibi secara istilah (Kara, 2012), syariah mempunyai tujuan untuk mewujudkan kemaslahatan manusia baik di dunia maupun di akhirat.

Syeh Nawab Naqvy (1996), (Hadi A. C., 2016), (Bahri et al., 2019) menekankan bahwa tujuan Maqashid Syariah adalah maslahat. Maqasid Syariah (Salman, 2014) merupakan prinsip bagaimana melakukan hal yang benar kepada orang-orang.

Maqasid al-syariah berkaitan dengan menjaga Agama (al-dien), menjaga akal (al'aql), menjaga jiwa (an-nafs), dan menjaga harta (al-mal/wealth) (Arsad et al., 2015), yang merupakan kemaslahatan pokok (K. Hadi, 2012) yang mencakup 5 (lima) aspek sebagaimana dijelaskan oleh Imam al-Syatibi yang intinya adalah membeirkan kemaslahatan kepada umat manusia. Pertama, menjaga agama (hifdz diin). Hal ini menjadi dasar diwajibkannya berdakwah, muamalah, dan jihad. Kedua, menjaga jiwa (hifdz nafs). Hal ini menjadi dasar untuk mewajibkan agar kebutuhan pokok dapat terpenuhi yang terdiri dari pangan, sandang, dan papan).

Ketiga, menjaga akal (hifdz aql). Hal ini menjadi dasar terhadap wajibnya menuntut ilmu selagi hayat dikandung badan serta menjadi haram untuk mengkonsumsi benda yang dapat memabukkan dan narkoba. Keempat, menjaga keturunan (hifdz nasl). Hal ini menjadi dasar wajibnya memperbaiki kualitas keturunan. dan menjadi haram melakukan zina dan perkawinan sedarah. Kelima, menjaga harta (hifdz maal). Hal 
ini menjadi dasar wajibnya harta untuk dikelola dan dikembanhgkan, karena dengan harta kita akan mampu menjaga empat tujuan sebelumnya.

Menurut Imam al-Syatibi (Attia, 2007), (Tarique1 et al., 2017), (Kara, 2012), kebutuhan manusia mempunyai 3 (tiga) tingkatan, yaitu: primer (dharuriyat), sekunder (hajiyat), dan tertier (tahsiniyah). Tingkatan Maqashid dan klasifikasi pengeluaran dapat dilihat pada tabel berikut:

Tabel 1.

Tingkatan Maqashid dan Klasifikasi Pengeluaran

\begin{tabular}{|l|l|}
\hline \multicolumn{1}{|c|}{$\begin{array}{c}\text { Hierarki Kebutuhan } \\
\text { Maqashid }\end{array}$} & \multicolumn{1}{c|}{ Contoh Penggunaan Dana } \\
\hline Primer (daruriyyat) & $\begin{array}{l}\text { - Pendidikan } \\
\text { - Kesehatan } \\
\text { - Pengeluaran untuk keamanan dan keadilan }\end{array}$ \\
\hline Sekunder (hajiyaat) & $\begin{array}{l}\text { - Kegiatan yang berkaitan dengan individu dan pengembangan sosial dan } \\
\text { ekonomi }\end{array}$ \\
\hline Tersier (tahsiniyyat) & $\begin{array}{l}\text { - Membangun klub olahraga, taman \& area rekreasi, } \\
\text { - Mengadakan kompetisi } \\
\text { - Menyediakan fasilitas hiburan bagi karyawan } \\
\text { - Apa pun yang meningkatkan kualitas hidup. }\end{array}$ \\
\hline
\end{tabular}

Sumber: Attia (2007), (Tarique1 et al., 2017), (Kara, 2012)

\section{METODE PENELITIAN}

Penelitian ini menggunakan metode kualitatif dengan pendekatan secara deskriptif. Menurut (Schurink, 2003) penelitian kualitatif bertujuan untuk menghasilkan pemahaman utuh yang diperoleh dari data dan kontekstual. Menurut (Taylor dan Bogdan, 1984), (Agusta, 2003), data kualitatif yang berbentuk deskriptif dapat dalam bentuk kata-kata lisan atau tulisan. Menurut (Creswell, 2014), penelitian kualitatif sangat bermanfaat ketika peneliti belum mendapati variabel penting yang akan diperiksa.

Penelitian kualitatif sifatnya adalah eksploratif, sehingga diperlukan literatur menjadi sangat bervariasi untuk melengkapi pengetahuan dasar dan teori (Anjar Wanto, 2019), (Efri Syamsul Bahri, Ariwibowo, dan Robbani, 2020), dengan cara mengumpulkan dan mempelajari literatur (Bastiar \& Bahri, 2019).
Penelitian kualitatif, menurut (Atmadja, 2013), juga disebut dengan studi kasus, karena objek penelitiannya bersifat unik dan kasuistis. Pengungkapan pemanfaatan Dana CSR untuk pencapaian Maqashid Syariah mengacu pada 5 (lima) dimensi kemaslahatan pokok Imam al-Syatibi (Arsad et al., 2015) ; (K. Hadi, 2012), antara lain: menjaga agama (hifdz diin), menjaga jima (hifdz nafs), menjaga akal (hifdz aql), menjaga keturunan (hifdz nasl), dan menjaga harta (hifdz maal). Pengumpulan data dilakukan dengan teknik studi Pustaka, wawancara, dan observasi. Metode keabsahan data dilakukan secara triangulasi. Menurut (Hussein, 2009), triangulasi merupakan salah satu langkah untuk melakukan validasi. Triangulasi juga dapat digunakan untuk menganalisis hasil wawancara untuk meneliti kebenarannya data empiris. Pada penelitian ini, data yang digunakan merupakan Program CSR pada tahun 2018. 


\section{PEMBAHASAN DAN HASIL}

\section{Pengungkapan CSR}

Pengungkapan CSR oleh PT. PLN Persero dicantumkan dalam Laporan Keuangan Tahunan dan Laporan Tahunan Sustainable dengan mengacu pada peraturan yang berlaku di Indonesia. Laporan Keuangan Tahunan dan Laporan Tahunan Sustainable mendapatkan opini Wajar dari Auditor eksternal.

Di dalam Undang-Undang Nomor 47 Tahun 2007 tentang Perseroan Terbatas, Peraturan Pemerintah Nomor 47 Tahun 2012, UndangUndang Nomor 22 Tahun 2001 tentang Minyak dan Gas Bumi, Undang-Undang Nomor 25 Tahun 2007 tentang Penanaman Modal Asing belum mengatur tentang jumlah anggaran yang dialokasikan untuk CSR. Aturan mengenai persentase tertentu untuk Dana yang akan dialokasikan pada program CSR dijelaskan pada pada Peraturan Menteri BUMN Nomor 236/MBU/2003 yang direvisi melalui Per-05/MBU/2007 tentang pelaksanaan Program Kemitraan dan Bina Lingkungan (PKBL).

Salah satu indikator untuk menilai komitmen perusahaan terkait isu sosial di sekitarnya adalah dengan membandingkan Dana CSR dengan Laba Bersih. Berdasarkan regulasi CSR, alokasi Dana PKBL sebesar 4 (empat) persen yang berasal dari Laba dialokasikan sebesar 2 (dua) persen untuk Kemitraan, dan 2 (dua) persen untuk Bina Lingkungan. Ketentuan tersebut berlaku untuk perusahaan yang termasuk dalam kategori BUMN.

Selain itu, ada Program Penilaian Peringkat Kinerja Perusahaan (Proper) yang merupakan program unggulan Kementerian Lingkungan Hidup dalam bentuk kegiatan pengawasan dan pemberian insentif dan atau disinsentif kepada penanggung jawab usaha dan/atau kegiatan.

Dalam laporan keuangan PT. PLN Persero, realisasi Dana CSR yang diungkapkan sebesar Rp126.89 Miliar dengan posisi Laba Bersih sebesar Rp11,575 Triliun. Jika Dana CSR dialokasikan sebesar 1\% dari Laba Bersih, maka PT. PLN Persero mestinya menggunakan Dana CSR sebesar Rp115.75 Miliar. Artinya, jumlah Dana CSR yang digunakan oleh PT. PLN Persero pada posisi di atas 1\%. Secara lebih rinci alokasi dana dan porsi Program CSR PT. PLN Persero dapat dilihat pada Tabel 2 .

Table 2

Program CSR PT. PLN Persero

\begin{tabular}{|c|l|r|l|}
\hline No & Program CSR & ALokasi (Rp) & \multicolumn{1}{c|}{ Porsi (\%) } \\
\hline 1 & Bantuan Korban Bencana Alam & $4,208,151,095$ & 3 \\
\hline 2 & Bantuan Pendidikan dan/atau Pelatihan & $21,087,372,873$ & 17 \\
\hline 3 & Bantuan Peningkatan Kesehatan & $17,903,364,199$ & 14 \\
\hline 4 & Bantuan Pengembangan Prasarana dan/atau Sarana Umum & $26,640,509,088$ & 21 \\
\hline 5 & Bantuan Sarana Ibadah & $18,046,879,497$ & 14 \\
\hline 6 & Bantuan Pelestarian Alam & $7,528,220,458$ & 6 \\
\hline 7 & Bantuan Sosial Kemasyarakatan untuk Pengentasan Kemiskinan & $28,332,120,576$ & 22 \\
\hline 8 & Administrasi & $3,143,025,555$ & 2 \\
\hline \multicolumn{2}{r|}{ Total } & $126,889,643,341$ & 100 \\
\hline
\end{tabular}

Sumber: Laporan Keuangan PT. PLN Persero (data diolah, 2020) 
Program CSR dialokasikan terdiri dari 7 (tujuh) program sebagaimana pada Tabel 2. Alokasi Dana CSR terbesar adalah pada Program Bantuan Sosial Kemasyarakatan untuk Pengentasan Kemiskinan mencapai 22\% dengan nilai bantuan Rp28,332,120,576. Sedangkan bantuan terkecil pada program Bantuan Korban Bencana Alam sebsar 3\% dengan nilai bantuan Rp4,208,151,095.

Pengungkapan CSR PT. PLN Persero pada dasarnya telah mengikuti standar internasional dan standar yang ditetapkan oleh pemerintah. Selain itu, PT. PLN Persero juga menggunakan standar Global Reporting Initiative (GRI) terbaru dalam bentuk Laporan Tahunan Sustainable. Laporan Sustainable PT. PLN Persero mengungkapkan program-program yang dilaksanakan dan program-program unggulannya dalam menjalakan kewajibannya sebagai bentuk tanggungjawab sosial perusahaan.

Selain ruang lingkup yang memadai, PT. PLN Persero juga mengungkapkan programprogram unggulannya dalam tanggung jawab sosial perusahaan, yakni: Program Pemberdayaan Desa, Program Sekolah Sungai, Program Vokasi, Program Rumah Kreatif BUMN, Program Bank Sampah, Program Konservasi Flora Dan Fauna, Program Renewable Energy, dan Program Sambung Listrik. Program-program tersebut akan berambah jumlahnya disetiap daerah di nusantara. Semua program CSR yang dijalankan bertujuan untuk mensejahterakan masyarakat bangsa Indonesia, agar berkurangnya tingkat kemiskinan di Indonesia, serta agar lebih perduli terhadap lingkungan sekitar.

\section{Pemanfaatan Dana CSR untuk Pencapaian Maqashid Syariah}

PT. PLN Persero merupakan BUMN dalam industri kelistrikan yang mengemban amanah besar bagi pelayanan kelistrikan di Indonesia. Pemanfaatan Dana CSR untuk pencapaian Maqashid Syariah dalam ranah CSR memberikan warna baru pada perusahaan. Dalam penelitian ini, ditemukan banyak dari program-program CSR PT. PLN Persero yang selaras dengan Maqashid Syariah sehingga mempunyai nilai mashlahah.

Pengungkapan pemanfaatan Dana CSR PT PLN dalam perspektif pencapaian Maqashid Syariah mencakup 5 (lima) aspek, sebagaimana pada Gambar 2. Pertama, menjaga agama (hifdz diin), dengan nilai bantuan sebesar Rp18,046,879,497,- atau 14.22\%. . Dalam nilai menjaga agama, hal yang diungkapkan oleh PT. PLN Persero adalah bantuan sarana dan prasarana umum rumah ibadah. Artinya dalam hal ini pemanfaatan Dana CSR untuk pencapaian hifdz diin dalam bentuk pemenuhan, perenovasian, sumbangan pembangunan rumah ibadah, dan sarana serta prasarana ibadah yang dilakukan. Selain itu terdapat kegiatan sosial lainnya seperti: santunan anak yatim, program buka puasa bersama, sunat massal, dan kegiatan sosial lainnya. Dalam skala internal, hifdz diin di PT. PLN Persero dilakukan dalam bentuk pembinaan kerohanian.

Kedua, menjaga jiwa (hifdz nafs), dengan nilai bantuan sebesar Rp22,111,515,294, - atau 17.43\%. Dalam konteks pemeliharaan jiwa, hal yang diungkapkan oleh PT. PLN Persero adalah bantuan untuk korban bencana alam, 
dalam bentuk penyediaan layanan listrik bagi

keberlangsungan kehidupan masyarakat korban bencana alam. Bantuan yang diberikan ini PT. PLN Persero dalam bentuk penyambungan listrik yang diberikan pada rumah Hunian Sementara
(HUNTARA). Bantuan lain adalah layanan kesehatan juga yang berguna untuk menjaga jiwa. Bantuan diberikan dalam bentuk penyediaan alat medis, yang digunakan oleh Tim Medis untuk layanan kesehatan kepada masyarakat.

Tabel 3

Pengungkapan Besaran dan Porsi Pemanfaatan Dana CSR untuk Pencapaian Maqasid Syariah

\begin{tabular}{|c|l|l|r|l|}
\hline No & \multicolumn{1}{|c|}{ Maqashid Syariah } & \multicolumn{1}{|c|}{ Program CSR } & (Rp) & Alokasi (\%) \\
\hline 1 & Menjaga Agama (hifdz diin) & Bantuan Sarana Ibadah & $18,046,879,497$ & 14.22 \\
\hline 2 & Menjaga Jiwa (hifdz nafs) & $\begin{array}{l}\text { Bantuan Korban Bencana Alam dan Bantuan } \\
\text { Peningkatan Kesehatan }\end{array}$ & $22,111,515,294$ & 17.43 \\
\hline 3 & Menjaga Akal (hifdz aql) & Bantuan Pendidikan dan/atau Pelatihan & $21,087,372,873$ & 16.62 \\
\hline 4 & $\begin{array}{l}\text { Menjaga Keturunan (hifdz } \\
\text { nasl) }\end{array}$ & $\begin{array}{l}\text { Bantuan Pengembangan Prasarana, Sarana } \\
\text { Umum, dan Bantuan Pelestarian Alam }\end{array}$ & $34,168,729,546$ & 26.93 \\
\hline 5 & Menjaga Harta (hifdz maal) & $\begin{array}{l}\text { Bantuan Sosial Kemasyarakatan untuk } \\
\text { Pengentasan Kemiskinan }\end{array}$ & $28,332,120,576$ & 22.33 \\
\hline 6 & Operasional & Biaya Administrasi & $3,143,025,555$ & 2.48 \\
\hline & & Jumlah & $126,889,643,341$ & 100 \\
\hline
\end{tabular}

Sumber: data diolah

Ketiga, menjaga akal (hifdz aql), dengan nilai bantuan sebesar Rp21,087,372,873,- atau 16.62\%. Poin pemeliharaan akal diungkapkan secara jelas oleh PT. PLN Persero yakni: bantuan program pendidikan dan program pelatihan guna untuk menunjang program lainnya yang berhubungan dengan kecerdasan intelektual. Seperti program beasiswa, program paltihan vokasi dan lain sebagainya. Selain itu PT. PLN Persero juga mengungkapkan hal lainnya dalam menjaga akal seperti: pendidikan untuk panti asuhan, pendidikan untuk pesantren dan lain sebagainya.

Perusahaan juga mengungkapkan komitmen PT. PLN Persero untuk meningkatkan kompetensi sumberdaya manusia untuk menunjang dunia usaha melalui program vokasi. Sasaran program vokasi adalah Sekolah Menengah Kejuruan (SMK) dan Perguruan Tinggi (PT). PT. PLN Persero juga mengungkapkan kegiatan lainnya terkait dengan pemeliharaan akal, yaitu: program beasiswa PLN dan PLN mengajar.

Program beasiswa PLN ditujukan untuk pelajar dan mahasiswa dari keluarga kurang mampu, nmaun mereka memiliki semangat untuk meningkatkan kualitas pendidikannya. Sedangkan, PLN mengajar bertujuan untuk mencerdaskan kehidupan bangsa, menumbuhkan minat, dan kepedulian kepada masyarakat Indonesia pada sektor ketenagalistrikan. Secara lebih rinci, program PLN Mengajar dapat dilihat pada tabel 3.

Selain itu terdapat pengungkapan lainnya yang memiliki nilai pemeliharaan akal ini, seperti program Sekolah Sungai, Rumah Kreatif BUMN, Bank Sampah, dan program Konservasi Flora dan Fauna. Sekolah Sungai diadopsi dari program eduwisata, dengan tujuan untuk memberikan edukasi sekaligus berwisata, dan mendukung pendidikan nonformal disekitar bantaran sungai. Sekolah Sungai yang berada di tiga provinsi, 
yaitu: DKI Jakarta, Jawa Tengah, dan Jawa Timur menargetkan untuk mencerdaskan masyarakat sungai.

Tabel 4.

Program PLN Mengajar Tahun 2018

\begin{tabular}{|l|l|l|l|}
\hline \multicolumn{1}{|c|}{ Kota } & \multicolumn{1}{|c|}{ Sekolah } & \multicolumn{1}{|c|}{ Pemateri } & \multicolumn{1}{c|}{ Materi } \\
\hline Makassar & $\begin{array}{l}\text { SMP Muhammadiyah 3, } \\
\text { SMA Muhammdiyah 2 }\end{array}$ & $\begin{array}{l}\text { General Manager PLN Wilayah } \\
\text { Sulselbar, Bambang Yusuf }\end{array}$ & $\begin{array}{l}\text { Motivasi Meraih Kesuksesan } \\
\text { Ketenagalistrikan }\end{array}$ \\
\hline Ninukan & $\begin{array}{l}\text { SMAN 1 Nunukan } \\
\text { Selatan }\end{array}$ & $\begin{array}{l}\text { General Manager PLN Wilayah } \\
\text { Kaltimra, Riza Novianto Gusam }\end{array}$ & $\begin{array}{l}\text { Wawasan Kebangsaan Bhinneka } \\
\text { Tunggal Ika, Wawasan Umum } \\
\text { Kelistrikan }\end{array}$ \\
\hline Mataram & SMAN 5 Mataram & $\begin{array}{l}\text { Transmisi dan Distribusi, Jhinni } \\
\text { Putra, serta Manajer SDM dan } \\
\text { Umum, Dedy Hidayat }\end{array}$ & $\begin{array}{l}\text { Proses produksi listrik, } \\
\text { Contact Center PLN 123 dan } \\
\text { pengetahuan kelistrikan lainnya }\end{array}$ \\
\hline Surabaya & SMAN 6 Surabaya & $\begin{array}{l}\text { General Manager PLN Disjatim, Bob } \\
\text { Saril }\end{array}$ & Kelistrikan dan Hemat Listrik \\
\hline Ambon & SMAN 11 Ambon & $\begin{array}{l}\text { General Manager PLN M2U, Djoko } \\
\text { Dwijatno }\end{array}$ & $\begin{array}{l}\text { Wawasan Kelistrikan dan } \\
\text { motivasi untuk berkontribusi di } \\
\text { sektor ketenagalistrikan }\end{array}$ \\
\hline
\end{tabular}

Sumber: data diolah

Keempat, menjaga keturunan (hifdz nasl), dengan nilai bantuan sebesar Rp34,168,729,546,atau $26.93 \%$. Pengungkapan menjaga keturunan oleh CSR PT. PLN Persero dalam bentuk bantuan kesehatan, pengembangan prasarana dan/atau sarana umum, dan pelestarian alam. Dalam hal ini PT. PLN Persero mengungkapkan bantuan kesehatan dalam bentuk peningkatan kesehatan masyarakat. Dalam bantuan pengembangan prasaran dan/atau sarana umum diungkapkan oleh PT. PLN Perseo dalam bentuk bantuan pengadaan sarana umum desa.

Selain itu, pemeliharaan keturunan juga diungkapkan dalam bentuk bantuan pelestarian alam, dalam bentuk penanaman kembali 1000 pohon di daerah tandus dan di daerah pantai yang rentan akan abrasi. Pemeliharaan ini berhubungan dengan pemeliharaan keturunan guna dimasa depan lingkungan yang asri dapat di lihat oleh generasi yang akan datang. Salah satu yang diungkapkan oleh perusahaan ialah mengenai Sekolah Sungai, Sekolah Sungai ini mengadopsi eduwisata. Yakni menjadikan sungai sebagai lokasi wisata dan belajar, atau dapat dikatakan dengan belajar sambil berekreasi sekaligus beraktivitas dengan santai di bantaran sungai. Contohnya adalah Sekolah Sungai Ciliwung yang berada di Srengseng Sawah DKI Jakarta. Daerah yang tadinya kumuh ini telah berubah menjadi asri dan bersih setelah dibangun sarana dan prasarana penunjang seperti penyediaan air bersih, MCK, dan perpustakaan. Kondisi ini telah menjadikan sungai sebagai magnet bagi masyarakat, sekaligus pola penyadaran bagi mereka untuk berpartisipasi secara aktif dalam melestarikan lingkungan, demi masa depan yang asri.

Kelima, menjaga harta (hifdz maal), dengan nilai bantuan sebesar Rp28,332,120,576,- atau 22.33\%. Poin pemeliharaan harta diungkapkan oleh PT. PLN Persero melalui bantuan sosial 
masyarakat untuk pengentasan kemiskinan, dalam bentuk Rumah Kreatif BUMN dengan tujuan untuk meningkatkan skill kreatif para UKM dalam berwirausaha. Selain itu terdapat rubrik khusus mengenai pengungkapan dalam menjaga harta. Dalam hal ini PT. PLN Persero Perusahaan memasok kebutuhan listrik dengan tarif listrikyang kompetitif agar dapat mendorong pertumbuhan ekonomi nasional. Perusahaan mengungkapkan bahwa kontribusi ekonomi yang diberikan oleh perusahaan kepada negara memiliki beberapa macam salah satunya ialah investasi.

Program lainnya adalah Pemberdayaan Desa yang memfokuskan pada peningkatan ekonomi desa dengan memunculkan Desa Wisata dan berbasis pada potensi dan budaya lokal. Dengan adanya Program Pemberdayaan Desa diharapkan dapat membantu perekonomian masyarakat dengan kearifan budaya lokal masing-masing. Sesuai dengan Maqashid Syariah yakni menjaga harta, pengungkapan oleh perusahaan dalam bentuk Pemberdayaan Desa memiliki memenuhi nilai Maqashid Syariah. Dimana Pemberdayaan Desa menjadi salah satu cara dalam nilai menjaga harta dengan memberdayakan masyarakat menjadi mandiri dari sisi ekonomi yang bermanfaat untuk memenuhi keberlangsungan hidupnya.

Tabel 5

Daftat Desa Binaan CSR PT. PLN Persero tahun 2018

\begin{tabular}{|c|l|l|l|}
\hline No & Program & Provinsi & Regional \\
\hline 1 & Silasihabung Festival, Desa Paropo & Sumatera Utara & Sumatera \\
\hline 2 & Kawasan Lampu Kita, Desa Rajabasa Jaya & Lampung & Sumatera \\
\hline 3 & $\begin{array}{l}\text { Revitalisasi Wisata Candi Muara Takus dan Kawasan } \\
\text { sekitarnya, Desa Muara Takus }\end{array}$ & Riau & Sumatera \\
\hline 4 & Program Sekolah Alam, Desa Rebo Air Anyir & Bangka Belitung & Sumatera \\
\hline 5 & Program Desa Wisata, Desa Pandansari & Jawa Tengah & Jawa Bagian Tengah \\
\hline 6 & Program Desa Wisata Lolong, Desa Lolong & Jawa Tengah & Jawa Bagian Tengah \\
\hline 7 & Balai Ekonomi Desa, Desa Ngadiharjo & DIY Yogyakarta & Jawa Bagian Tengah \\
\hline 8 & Peningkatan Kualitas Atsiri dan Budidaya Bunga & DIY Yogyakarta & Jawa Bagian Tengah \\
\hline 9 & Agrowisata Sungai Mudal, Desa Jatimulyo & Jawa Tengah & Jawa Bagian Tengah \\
\hline 10 & Wisata Berburu Madu & $\begin{array}{l}\text { Nusa Tenggara } \\
\text { Barat }\end{array}$ & $\begin{array}{l}\text { Jawa Bagian Timur, Bali, dan } \\
\text { Nusa Tenggara }\end{array}$ \\
\hline
\end{tabular}

Sumber: data diolah

\section{PENUTUP}

\section{Kesimpulan}

Pengungkapan CSR pada PT. PLN Persero menjelaskan bahwa total dana yang dialokasikan untuk program CSR ialah sebesar Rp126,89 Milyar. Sedangkan menurut Peraturan Menteri BUMN Nomor 236/MBU/2003 yang direvisi melalui Per-05/MBU/2007 tentang pelaksanaan Program Kemitraan dan Bina Lingkungan, alokasi
Dana PKBL 4\% dari laba yang terdistribusi sebesar 2\% untuk Kemitraan, dan 2\% untuk Bina Lingkungan. Regulasi ini hanya berlaku untuk perusahaan yang berstatus BUMN. Sedangkan, Proper menetapkan persentase minimal antara Dana CSR dengan laba bersih sebesar 1\%.

Pengungkapan pemanfaatan Dana CSR untuk pencapaian Maqashid Syariah mencakup 5 (lima) aspek, yaitu: menjaga agama (hifdz diin) dengan 
nilai bantuan sebesar Rp18,046,879,497,- atau 14.22\%, menjaga jiwa (hifdz nafs) dengan nilai bantuan sebesar Rp22,111,515,294, - atau 17.43\%, menjaga akal (hifdz aql) dengan nilai bantuan sebesar Rp21,087,372,873,- atau 16.62\%, menjaga keturunan (hifdz nasl) dengan nilai bantuan sebesar Rp34,168,729,546,- atau 26.93\%, dan menjaga harta (hifdz maal) dengan nilai bantuan sebesar Rp28,332,120,576,- atau 22.33\%, serta untuk keperluan Operasional program sebesar Rp3,143,025,555,- atau 2.48\%. Dengan demikian, pemanfaatan Dana CSR untuk pencapaian Maqashid Syariah yang paling besar pada aspek menjaga keturunan (hifdz nasl) dengan nilai bantuan sebesar Rp34,168,729,546,- atau 26.93\%, sedangkan yang paling sedikit pada aspek menjaga agama (hifdz diin) dengan nilai bantuan sebesar Rp18,046,879,497,- atau 14.22\%.

Pemanfaatan Dana CSR untuk pencapaian Maqashid Syariah pada aspek menjaga agama (hifdz diin) diungkapkan oleh PT PLN Persero dalam bentuk bantuan sarana dan prasarana umum rumah ibadah, santunan anak yatim, program buka puasa bersama, sunat massal, dan kegiatan sosial lainnya. Pemanfaatan Dana CSR untuk pencapaian Maqashid Syariah pada aspek menjaga jiwa (hifdz nafs) diungkapkan dalam bentuk bantuan kemanusiaan kepada korban bencana alam diantaranya: bantuan program penyambungan listrik di hunian sementara (HUNTARA), penyediaan alat medis.

Pemanfaatan Dana CSR untuk pencapaian Maqashid Syariah pada aspek menjaga akal (hifdz aql) diungkapkan dalam bentuk program pendidikan dan pelatihan, beasiswa, program palatihan vokasi dan lain sebagainya, pendidikan untuk panti asuhan, pendidikan untuk pesantren dan lain sebagainya, beasiswa PLN, dan PLN mengajar program beasiswa PLN, program Sekolah Sungai, Rumah Kreatif BUMN, Bank Sampah, dan program Konservasi Flora dan Fauna. Pemanfaatan Dana CSR untuk pencapaian Maqashid Syariah pada aspek menjaga keturunan (hifdz nasl) diungkapkan dalam bentuk bantuan kesehatan, bantuan pengembangan prasarana dan/atau sarana umum, dan bantuan pelestarian alam. Sedangkan Pemanfaatan Dana CSR untuk pencapaian Maqashid Syariah dalam aspek menjaga harta (hifdz maal) diungkapkan oleh PT. PLN Persero dalam bentuk bantuan sosial masyarakat untuk pengentasan kemiskinan, misalnya: Rumah Kreatif BUMN, dan Program Pemberdayaan Desa untuk meningkatan taraf ekonomi masyarakat desa.

\section{Saran}

Hasil penelitian ini sebagiamana diuraikan di atas, sekaligus memberikan wawasan baru tentang kontribusi Dana CSR untuk pencapaian Maqashi Syariah. Oleh karena itu, dengan adanya keterbatasan pada penelitian ini, maka diperlukan penelitian lebih lanjut untuk mengukur pengaruh dana CSR pada pencapaian Maqashid Syariah menggunakan metode lain. Selain itu, penelitian selanjutnya dapat menambahkan data dalam beberapa tahun dan menambahkan jumlah obyek pada beberapa perusahaan milik negara lainnya.

\section{DAFTAR KEPUSTAKAAN}

Agusta, I. (2003). Qualitative Data Collection and Analysis Techniques. Pusat Penelitian Sosial Ekonomi. Litbang Pertanian, Bogor, 27 Pebruari 2003, 1-11. 
Arsad, S., Ahmad, R., Nazjmi, W., Fisol, M., Said, R., \& Haji-othman, Y. (2015). Maqasid Shariah in Corporate Social Responsibility of Shari'ah Compliant Companies. Research Journal of Finance and Accounting, 6(6), 239-248.

Atmadja, A. T. (2013). Methodology and Qualitative Research Struggles in the Domain of Accounting. Jurnal Akuntansi Profesi, 3(2), 122-141. https://doi.org/http://dx.doi. org/10.23887/jap.v3i2

Bahri, E. S., Aslam, M. M. M., Hasan, A. A. H., \& Wibowo, H. (2019). Maqasid al-Shariah in Micro-Entrepreneurs Development: an Overview. International Conference of Zakat 2019, 258-267. https://doi.org/10.37706/ iconz.2019.182

Bastiar, Y., \& Bahri, E. S. (2019). Model Pengkuran Kinerja Lembaga Zakat di Indonesia. ZISWAF : Jurnal Zakat Dan Wakaf, 6(1), 43. https://doi. org/10.21043/ziswaf.v1i1.5609

Čavalić, A. (2018). Corporate Social Responsibility in Islam. 6th International Conference on Islam and Liberty, November, 14-15.

Creswell,J.W. (2014). Research Design: Qualitative, Quantitative, and Mixed Method. In Research Design Qualitative, Quantitative, and Mixed Methods Approaches. SAGE Publications, Inc.

Dermawan, D., \& Deitiana, T. (2014). Factors that influence Corporate Social Responsibility Disclosure. Jurnal Bisnis Dan Akuntansi, 16(2), 158-165. https://doi.org/https://doi. org/10.34208/jba.v16i2.86

Finarti, A., \& Putra, P. (2015). Implementation of Maqashid Al-Syariáh on the Implementation of Islamic Bank CSR: Case Study at PT. BRI Syariah Bank. SHARE, 4(1), 37-66. https:// doi.org/http://dx.doi.org/10.22373/share. v4i1.724

Hadi, A. C. (2016). Corporate Social Responsibility and Corporate Zakat in Islamic Economic Law Perspective. Jurnal Ilmu Syariah, 16(2), 229-240. https://doi.org/DOI: 10.15408/ ajis.v16i2.4453

Hadi, K. (2012). Implementation of Maqashid Syariah as an Indicator of Islamic Companies. Jurnal Al-Azhar Indonesia Seri Pranata Sosial, 1(3), 140-150.

Hadi, N. (2011). Interaction of Social Responsibility, Social Performance, Financial Performance, and Extent of Social Disclosure (Test the Motive Behind Corporate Social Responsibility Going public in Indonesia). MAKSIMUM, 1(2), 59-67. https://doi. org/10.26714/mki.v1i2.247

Hussein, A. (2009). The use of Triangulation in Social Sciences Research: Can qualitative and quantitative methods be combined? Journal of Comparative Social Work, 1-12. https://doi.org/https://doi.org/10.31265/ jcsw.v4i1.48

Kamil, A., \& Herusetya, A. (2012). Effect of Company Characteristics on the Disclosure of Corporate Social Responsibility Activities. Media Riset Akuntansi, 2(1), 1-17.

Kara, M. (2012). Al-Syatibi's Thoughts on Maslahah and Its Implementation in Sharia Economic Development. Jurnal Assets, 2(2), 173-184. 
Kriyantono, R. (2015). Public Relations and Corporate Social Responsibility in Mandatory Approach Era in Indonesia. Procedia - Social and Behavioral Sciences, 211(September), 320-327. https://doi.org/10.1016/j. sbspro.2015.11.041

Kusumo, J. M. T., \& Juniarti. (2015). Pengaruh Corporate Social Reponsibility Terhadap Respon Investor Dalam Sektor Industri Barang Konsumsi. Business Accounting Review, 3(1), 212-222.

Maqbool, S., \& Zameer, M. N. (2018). Corporate social responsibility and financial performance: An empirical analysis of Indian banks. Future Business Journal, 4(1), 84-93. https://doi.org/10.1016/j.fbj.2017.12.002

Marnelly, T. R. (2012). Corporate Social Responsibility (CSR): Tinjauan Teori dan Praktek di Indonesia. Jurnal Aplikasi Bisnis, 2(2), 49-59.

Masoud, N. (2017). How to win the battle of ideas in corporate social responsibility: the International Pyramid Model of CSR. Masoud International Journal of Corporate Social Responsibility, 2(4). https://doi. org/10.1186/s40991-017-0015-y

Mihriban, C. A., \& Harun, K. (2017). The Corporate Sustainability Solution: Triple Bottom Line. The Journal of Accounting and Finance, July, 18-34.

Mitra, N., \& Schmidpeter, R. (2020). Mandated Corporate Social Responsibility: Evidence from India. Springer. https://doi. org/10.1007/978-3-030-24444-6 (C)
Nayenggita, G. B., Raharjo, S. T., \& Resnawaty, R. (2019). Praktik Corporate Social Responsibility (CSR) di Indonesia. Jurnal Pekerjaan Sosial, 2(1), 61-66. https:// doi.org/https://doi.org/10.24198/focus. v2i1.23119

Nugroho, L., Utami, W., Sanusi, Z. M., \& Setiyawati, H. (2018). Corporate Culture and Financial Risk Management in Islamic Social Enterprises (Indonesia Evidence). International Journal of Commerce and Finance, 4(2), 12-24.

Purwanto, A. (2011). Effect of Industry Type, Company Size, Profitability on Corporate Social Responsibility. Jurnal Akuntansi \& Auditing, 8(1), 12-29. https://doi.org/ https://doi.org/10.14710/jaa.8.1.12-29

Putri, A. K., Sudarma, M., \& Purnomosidhi, B. (2016). Effect of Corporate Social Responsibility on Company Value with Company Size and Number of Board of Commissioners as Moderating Variables (Study of Manufacturing Companies listed on the Indonesia Stock Exchange). Jurnal Aplikasi Manajemen (JAM), 14(2). https:// doi.org/http://dx.doi.org/10. 18202/ jam23026332.14.2.16

Putri, R. A., \& Christiawan, Y. J. (2014). Pengaruh Profitabilitas, Likuiditas, dan Leverage terhadap Pengungkapan Corporate Social Responsibility (Studi pada PerusahaanPerusahaan yang Mendapat Penghargaa ISRA dan Listed (Go-Publik) di Bursa Efek Indonesia (BEI) 2010-2012). Business Accounting Review, 2(1), 61-70. 
JURNAL IMARA

Saifi, M. (2020). Corporate Social Responsibility Manufaturing Company in Indonesia. Journal of Applied Management (JAM), 18(2), 383390. https://doi.org/http://dx.doi.org/10. 21776/ub.jam.2020.018.02.19

Salman, S. (2014). Ethics \& Governance (Issue July). Chartered Islamic Finance Professional (CIFP) INCEIF - The Global University of Islamic.

Schurink, W. J. (2003). Qualitative Research In Management And Organisational Studies With Reference To Recent South African Research. SA Journal of Human Resource Management, 1(3), 2-14. https://doi. org/10.4102/sajhrm.v1i3.25

Syafii, M., Sanrego, Y. D., \& Taufiq, M. (2012). An Analysis of Islamic Banking Performance : Maqashid Index Implementation in Indonesia and Jordania. Journal of Islamic Finance, 1(1), 12-29.
Tarique1, K. M., Ahmed, M. U., Hossain, D. M., \& Momen, M. A. (2017). Maqasid al-Shariah in CSR Practices of the Islamic Banks: A Case Study of IBBL. Journal of Islamic Economics, Banking and Finance, 13(3), 47-63.

Türker, D. (2015). Contrasting Instrumental Views on Corporate Social Responsibility: Shortterm Versus Long-term Profit Orientation Approach. Procedia - Social and Behavioral Sciences, 207, 568-576. https://doi. org/10.1016/j.sbspro.2015.10.128

Wuttichindanon, S. (2017). Kasetsart Journal of Social Sciences Corporate social responsibility disclosure $d$ choices of report and its determinants: Empirical evidence from fi rms listed on the Stock Exchange of Thailand. Kasetsart Journal of Social Sciences, 38(2), 156-162. https://doi.org/10.1016/j. kjss.2016.07.002

132 || Siti Humairoh, Efri Syamsul Bahri, Ahmad Bisyri Syakur, Rianti Pratiwi 